\title{
Research on Burn Pattern Characteristics of Polypropylene fiber and Polyvinyl chloride coil Flooring Materials Loaded By Gasoline
}

\author{
Jing JIN $^{\mathrm{a}}$ and Bingbing $\mathrm{CHEN}^{\mathrm{b}}$ \\ Chinese People's Armed Police Force Academy, Langfang 065000, Hebei, China \\ jinj@iccas.ac.cn', b584058304@qq.com
}

\begin{abstract}
Gasoline, as one of the flammable liquids, is used commonly in arson. Due to its typical fluidity and permeability, particular burn patterns can be formed in fire scene. In order to provide references for fire investigators to collect trace evidences and identify fire cause accurately, the burn patterns on different flooring materials are investigated in this paper. Two polymer flooring materials (Polypropylene fiber and Polyvinyl chloride coil) were selected in the experiments to study the burn pattern characteristics by simulating the fire scene. By comparing the difference of the burning pattern with and without gasoline, rules of pattern characteristics on different material surface have been summarized. Meanwhile, fire extinguishing style was considered in this work. The results show that the burn pattern characteristics become remarkably different when the flooring materials loaded by gasoline. In addition, fire extinguishing style has a great impact on the burn patterns, such as the carbonized degree, the residual shape and the fire traces. It is believed that the results in this paper would provide important guidance for investigation on arson which applied gasoline as the combustion improver.
\end{abstract}

\section{Introduction}

It is well known that arson caused great lose and terror to the society due to its seriousness, viciousness and intentionally subjectiveness, which imposed high pressure for fire investigation as well. Flammable liquids as the combustion improver was applied in arson originated from its high fire risk, such as gasoline, paint thinner and alcohol. Among these combustion improvers, gasoline is applied in more than $90 \%$ arson statistically. Due to its typical fluidity and permeability, particular burn patterns can be formed in fire scene, which are important clues for investigators to collect material evidence. Furthermore, these preserved traces are influenced not only by the nature of the flammable liquids but by the condition of the substrates and the environment of the fire [1-3]. Nowadays, some researched have been applied to study the typical burning patterns of the gasoline on different flooring materials [4-8]. Guofu Liang and Wanfu Liu have studied the influence of the amount and

* Corresponding author: jinj@iccas.ac.cn 
the spilling style of the gasoline on the burning traces on different kinds of floors materials [7-8]. Although these results provide important information of the traces study in fire scene, the detailed parameters, such as the time to extinguish and the extinguish style, have not been explored, and comparison experiment has not been designed to simulated the fire scene, especially on the new types floor materials. In order to provide references for fire investigators to collect trace evidences and identify fire cause accurately, the burn patterns on different flooring materials are investigated in this paper. Two typical flooring materials, Polypropylene (PP) fiber and Polyvinyl chloride (PVC) coil were selected in the experiments to study the burn pattern characteristics by simulating the fire scene. By comparing the difference of the burning patterns with and without gasoline, rules of pattern characteristics on different material surface have been summarized. Meanwhile, fire extinguishing style was considered in this work.

\section{Experiment}

\subsection{Materials}

$50 \mathrm{ml}$ gasoline was applied in each experiment.

Table 1. The Information Of The Materials Selected In The Study

\begin{tabular}{cccc}
\hline Materials & Size & Amount & Number \\
\hline PP fiber & $50 \mathrm{~cm} \times 50 \mathrm{~cm}$ & 4 & $1-1,1-2,1-3,1-4$ \\
PVC coil & $60 \mathrm{~cm} \times 60 \mathrm{~cm}$ & 4 & $2-1,2-2,2-3,2-4$ \\
\hline
\end{tabular}

\subsection{Preparation of the burning pattern}

All the traces are prepared by simulating the fire scene. Taking PP fiber floor for example, the pad was laid on the floor of the fire science lab firstly; $50 \mathrm{ml}$ gasoline was applied in each experiment if used. The fire is ignited by two means, the gasoline or the burning wood, and the fire was put out by the spill water or natural out. Four kinds of burning patterns were prepared using one floor material. Similarly, the burning patterns on PVC coil floor were prepared.

Table 2. The Means To Prepare The Burning Traces

\begin{tabular}{cc}
\hline Traces types & $\begin{array}{c}\text { Materials } \\
\text { number }\end{array}$ \\
\hline $\begin{array}{c}\text { Fire is ignited by gasoline and is out by itself } \\
\text { Fire is ignited by gasoline and is out by fire fighting water }\end{array}$ & $1-1,2-1$ \\
Fire is ignited by burning wood and is out by itself & $1-2,2-2$ \\
Fire is ignited by burning wood and is out by fire fighting & $1-3,2-3$ \\
water & $1-4,2-4$ \\
\hline
\end{tabular}

\subsection{Records of the results}

The digital camera (Nikon D7000) was used to record the preformed traces after the burning pattern formed. 


\section{Results and Discussion}

(a) The burning pattern on the PP fiber

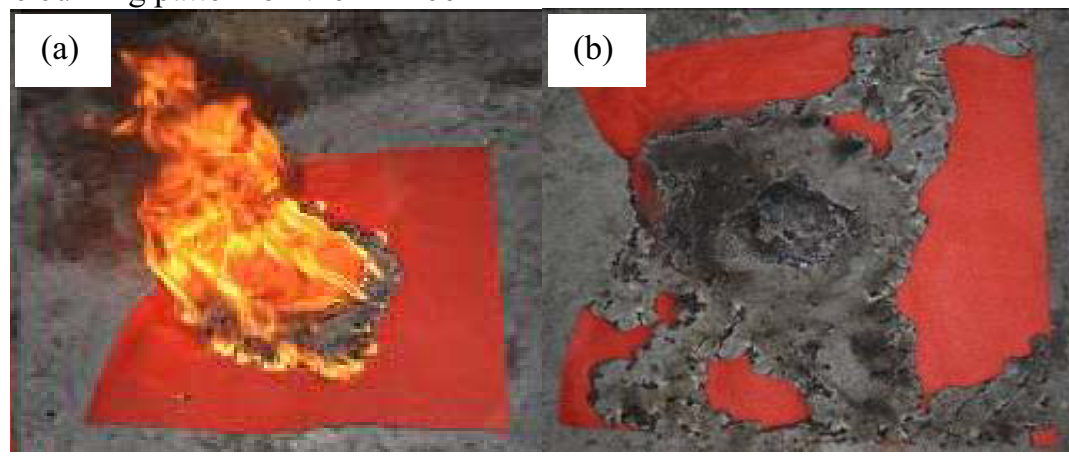

Fig. 1. The combustion process of the PP fiber loaded by $50 \mathrm{ml}$ gasoline, and the fire was out naturally (a) the burning PP fiber and (b) the burning pattern formed on the PP fiber after the fire went out by itself.

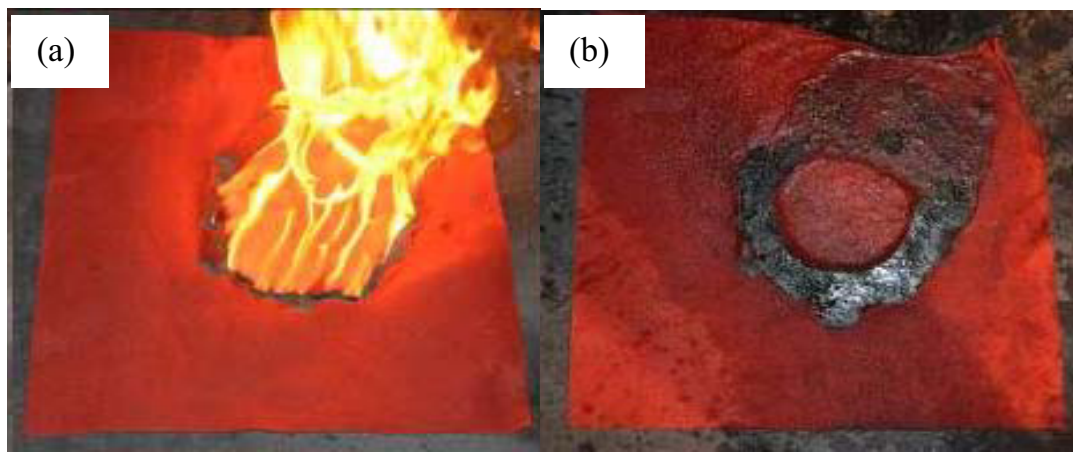

Fig. 2. The combustion process of the PP fiber loaded by $50 \mathrm{ml}$ gasoline, and the fire was out by water. (a) the burning PP fiber and (b) the burning pattern formed on the PP fiber after the fire went out by water.

The burning patterns formed on the PP fiber when loaded by gasoline were shown in Figure1, to study the influence of extinguishment style on the burning pattern, we put out the fire by water forcibly during the combustion process. On the other hand, to analyze the burning traces clearly by comparing the traces caused by the combustion improver and other combustion in, the traces formed by other combustions (the burning wood in this work) were studied as well, which were shown in Figure 3 and 4.

The characteristic of the burning traces was compiles in Table 3 by comparing these traces together. Here, the factors of ignition and extinguishment style were considered in details.
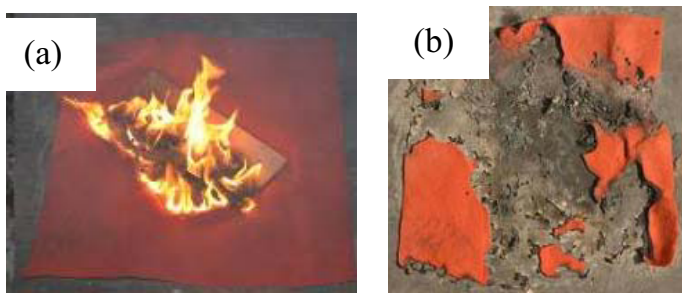

Fig. 3. The combustion process of the PP fiber loaded by burning wood, and the fire was out by itself. (a) the burning PP fiber ignited by the burning wood and (b) the burning pattern formed on the PP fiber after the fire went out by itself. 

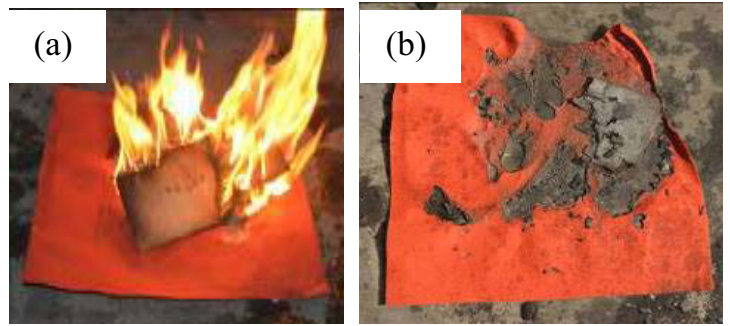

Fig. 4. The combustion process of the PP fiber loaded by burning wood, and the fire was out by water (a) the burning PP fiber ignited by the burning wood and (b) the burning pattern formed on the PP fiber after the fire went out by water.

Table 3. The Characteristics of the Burning Traces Reserved On The Pp Fiber

\begin{tabular}{|c|c|c|}
\hline $\begin{array}{l}\text { Extinguishment } \\
\text { style }\end{array}$ & Loaded by gasoline & $\begin{array}{l}\text { Ignited by burning } \\
\text { wood }\end{array}$ \\
\hline $\begin{array}{l}\text { the fire was extinguished } \\
\text { naturally }\end{array}$ & $\begin{array}{l}\text { There was few PP fire left } \\
\text { after combustion, obvious flow } \\
\text { and combustion traces on the fiber } \\
\text { with the circle shape can be found. } \\
\text { The continuity of the burning } \\
\text { traces is kept well with the smooth } \\
\text { charring surface. }\end{array}$ & $\begin{array}{l}\text { The PP pad was burn } \\
\text { through with irregular } \\
\text { shape, the carbonized } \\
\text { areas were continuious. }\end{array}$ \\
\hline $\begin{array}{l}\text { the fire was extinguished by } \\
\text { water forcibly }\end{array}$ & $\begin{array}{l}\text { There were more PP fiber floor } \\
\text { materials left, the traces exhibited } \\
\text { a typical circle, wher the edge was } \\
\text { serious charred but the inner was } \\
\text { saved well }\end{array}$ & $\begin{array}{l}\text { The most remarkable } \\
\text { difference of the traces } \\
\text { formed under this } \\
\text { condition is the } \\
\text { carbonation of the pad is } \\
\text { weaker and uneven on the } \\
\text { pad; there is more PP fiber } \\
\text { left. Simultaneously, there } \\
\text { was some wooden } \\
\text { charring reserved on the } \\
\text { pad. }\end{array}$ \\
\hline
\end{tabular}

The burn patterns formed on the PVC coil floor were shown from Figure 5 to Figure 8, and the characteristics of the burning traces were compiles in Table 4 by comparing these traces together. Here, the factors of ignition and extinguishment style were considered in details as well.

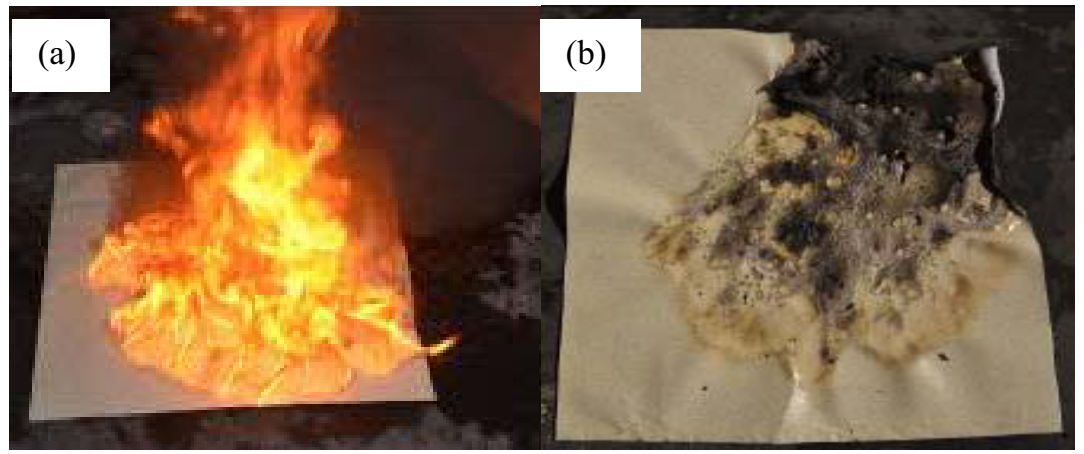

Fig. 5. The combustion process of the PVC coil floor loaded by $50 \mathrm{ml}$ gasoline, and the fire was out naturally (a) the burning PVC coil floor and (b) the burning pattern formed on the PVC coil floor after the fire went out by itself. 


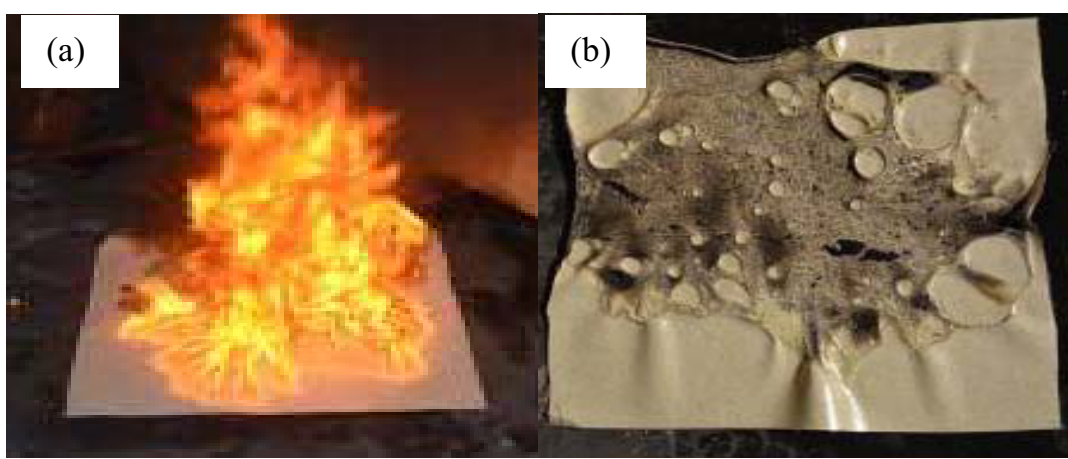

Fig. 6. The combustion process of the PVC coil floor loaded by $50 \mathrm{ml}$ gasoline, and the fire was out by water (a) the burning PVC coil floor and (b) the burning pattern formed on the PVC coil floor after the fire went out by water.

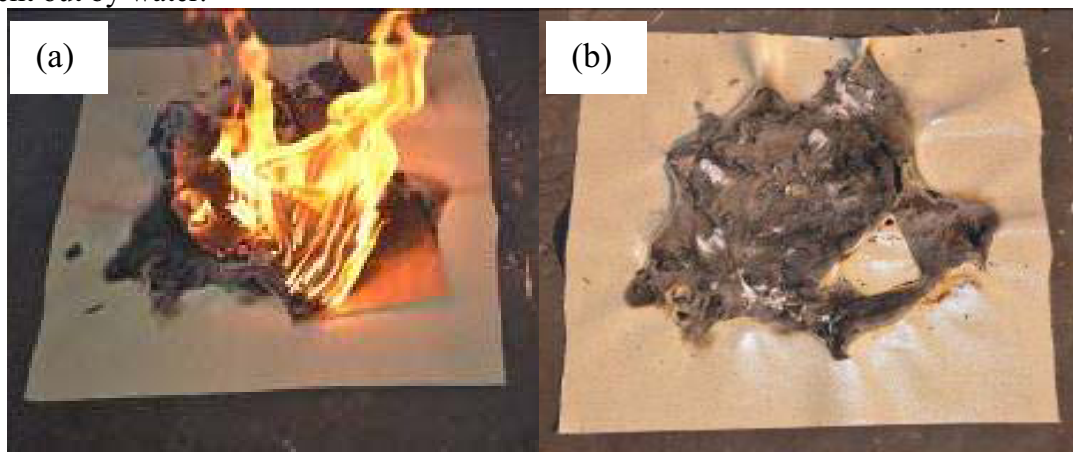

Fig. 7. The combustion process of the PVC coil floor loaded by burning wood, and the fire was out by itself (a) the burning PVC coil floor and (b) the burning pattern formed on the PVC coil floor after the fire went out by itself.

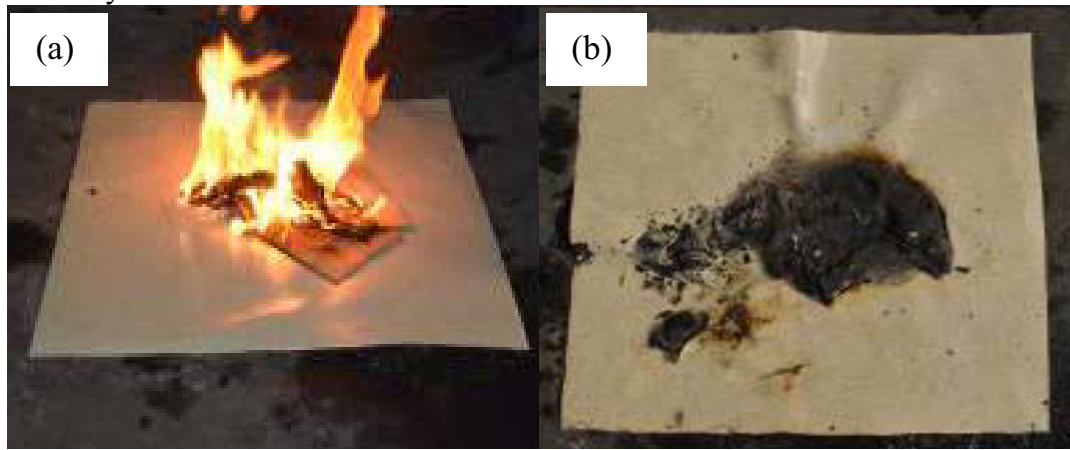

Fig. 8. The combustion process of the PVC coil floor loaded by burning wood, and the fire was out by water (a) the burning PVC coil floor and (b) the burning pattern formed on the PVC coil floor after the fire went out by water. 
Table 4. The Characteristics of the Burning Traces Reserved on The pvc Coil Floor

\begin{tabular}{|c|c|c|}
\hline $\begin{array}{l}\text { Extinguishment } \\
\text { style }\end{array}$ & Loaded by gasoline & $\begin{array}{l}\text { Ignited by burning } \\
\text { wood }\end{array}$ \\
\hline $\begin{array}{l}\text { the fire was extinguished } \\
\text { naturally }\end{array}$ & $\begin{array}{l}\text { There are much less concave } \\
\text { holes on the surface of the PVC } \\
\text { coil floor material, but the PVC } \\
\text { was seriously carbonized with } \\
\text { obvious combustion traces. }\end{array}$ & $\begin{array}{l}\text { There was serious } \\
\text { charring for the PVC coil, } \\
\text { and fewer wooden was left } \\
\text { on the floor materials. }\end{array}$ \\
\hline $\begin{array}{l}\text { the fire was extinguished } \\
\text { by water forcibly }\end{array}$ & $\begin{array}{l}\text { There are more concave } \\
\text { holes on the surface of the PVC } \\
\text { coil floor material, where the } \\
\text { PVC materials were kept well } \\
\text { with little carbonization. }\end{array}$ & $\begin{array}{l}\text { There was few charring } \\
\text { formed on the PVC coil } \\
\text { floor, and some wooden } \\
\text { was left on the floor } \\
\text { materials. The egg-white } \\
\text { color are appeared in some } \\
\text { local regions. }\end{array}$ \\
\hline
\end{tabular}

\section{Summary}

The characteristic of the burning traces is affected by the nature of the combustion itself as well the properties of the matrix, meanwhile, the condition of the fire origin, such as the terrain, the direction of the wind and the burning time, will impose effect on the traces. Once the gasoline loaded on the PP fiber, there are some stable traces with the color change. However, the pad has not been burn though, and there was little distortion. While for the combustible PVC coil floor, the carbonization traces will be reserved on the matrix, the PVC is likely to be burn through from its edge with typical bulging phenomenon on the floor material, which made the surface much rougher. For the two floor materials, there are remarkable flowing. When the fire was put off by water, the burning traces will be influenced obviously by the water, especially for the one loaded with gasoline, as water will change the flow of the combustion improver.

\section{References}

1. J. J. Lentini, Persistence of floor coating solvents, Forensic Science 46 (2001) $1470-1473$

2. E. Stauffer, Concept of pyrolysis for fire debris analysts, Scientific \& Justice 43 (2003) 29-40.

3. J.R. Almirall, K.G. Furton, Characterization of background and pyrolysis products that may interfere with the forensic analysis of fire debris, Journal of Analytical\&Applied Pyrolysis 71 (2004) 51-67.

4. G.F. Liang, G.H. Wang, Z.B. Lu, X. Wang, W. Zheng, Research on burning pattern characteristics of flooring materials ignited by gasoline, Fire Science and Technology 29 (2010) 876-884.

5. W.F. Liu, X.M. Wan, Z.B. Lu, J.W. Wang, M.H. Ge, W.Q. Qi, Experiments on fire characteristics of floorings ignited by gasoline, Fire Science and Technology 29 (2010) 871-875. 